\title{
Hydrazides in the reaction with hydroxypyrrolines: less nucleophilicity - more diversity
}

\author{
Dmitrii A. Shabalin, Evgeniya E. Ivanova, Igor A. Ushakov, Elena Yu. Schmidt \\ and Boris A. Trofimov*
}

\author{
Full Research Paper \\ Address: \\ A. E. Favorsky Irkutsk Institute of Chemistry, Siberian Branch of the \\ Russian Academy of Sciences, 1 Favorsky St, 664033 Irkutsk, \\ Russian Federation \\ Email: \\ Boris A. Trofimov ${ }^{*}$ - boris_trofimov@irioch.irk.ru \\ * Corresponding author \\ Keywords: \\ hydrazides; pyridazines; pyrrolines; recyclization; ring expansion
}

\author{
Beilstein J. Org. Chem. 2021, 17, 319-324. \\ https://doi.org/10.3762/bjoc.17.29 \\ Received: 20 November 2020 \\ Accepted: 21 January 2021 \\ Published: 29 January 2021 \\ Associate Editor: I. Baxendale \\ (C) 2021 Shabalin et al.; licensee Beilstein-Institut. \\ License and terms: see end of document.
}

\begin{abstract}
Expedient protocols for the synthesis of three types of highly functionalized azaheterocyclic scaffolds (dihydropyridazines, tetrahydropyridazines, and partially saturated tricyclic systems) from readily available hydroxypyrrolines and hydrazides are described. The directions of the transformation of a common initial intermediate, namely a Brønsted acid-activated hydroxypyrroline, depend on the reaction conditions and the structure of the hydrazides.
\end{abstract}

\section{Introduction}

Di- and tetrahydropyridazines are valuable heterocyclic motifs which are utilized as key fragments of influenza neuraminidase inhibitors [1], nonsteroidal progesterone receptor regulators [2,3], anti-inflammatory [4], antihypertensive and spasmolytic [5-7] agents (Figure 1). It is due to their prospects in drug design that a search for effective synthetic protocols to construct partially saturated pyridazine scaffolds is both highly topical and necessary.

Recently, we have developed a convenient approach to the 1,4dihydropyridazine core based on the Brønsted acid-catalyzed regioselective recyclization of 5-hydroxypyrrolines (assembled in a one-pot manner from ketoximes and acetylene gas [8,9] or<smiles>[R]N[C@H]1CC(C(=O)O)=NN(C(=O)C(CC)CC)[C@H]1NC</smiles>

ref. [1]<smiles>O=C(c1ccc([N+](=O)[O-])cc1)N1CCCC(c2ccccc2)=N1</smiles>

ref. [2]<smiles>CCOC(=O)C1=C(C)N(C(=O)c2ccccc2)N=C(C)C1c1ccccc1</smiles>

ref. [5]
Figure 1: Biologically active di- and tetrahydropyridazines.

calcium carbide [10]) with hydrazines (Scheme 1) [11,12]. The reaction is operationally simple and tolerates a wide range of hydrazines including alkyl-, aryl-, and hetarylhydrazines [11] as well as semicarbazide and its derivatives [12]. 
previous works (ref. [11,12])<smiles>[R]C1=NC(O)CC1[R]</smiles>

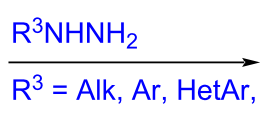

$\mathrm{CONH}_{2}, \mathrm{CONHPh}$

this work<smiles>[R][R]1=NN([R3])C=CC1[R]</smiles>
$R^{3}$

$$
\text { 致 }
$$

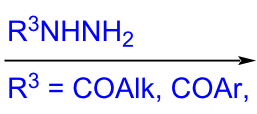<smiles>[R][R]1=NN([R])C=CC1[R]</smiles><smiles>[R]NNC1CC([R])([R])N([R])N=C1[R]</smiles>

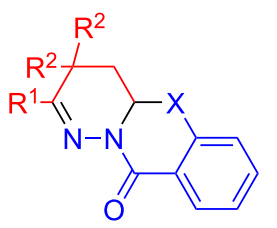

Scheme 1: Recyclization of hydroxypyrrolines with hydrazine derivatives.

However, the scope of this method with a special emphasis on the nature of hydrazine derivatives still remains obscure. Meeting this challenge becomes particularly important in view of the significance of the less nucleophilic hydrazides as $\mathrm{N}-\mathrm{N}-$ bond containing starting materials in drug discovery [13$16]$.

Herein, we report how a lower nucleophilicity of the hydrazides diversifies the recyclization of 5-hydroxypyrrolines and results in the chemoselective formation of highly functionalized azaheterocyclic scaffolds. Such a short-cut to partially saturated azaheterocyclic scaffolds meets the interests of modern medicinal chemistry which today focuses on the study of partially saturated molecules because $\mathrm{sp}^{3}$ carbon centers make the molecules potentially chiral and 3D structured, which improves the odds for drug discovery [17].

\section{Results and Discussion}

On the basis of our previous works $[11,12]$ the reaction of 3,3dimethyl-5-hydroxy-2-phenyl- $\Delta^{1}$-pyrroline (1a) with an equimolar amount of benzohydrazide (2a) was initially performed in the presence of trifluoroacetic acid (TFA, $10 \mathrm{~mol} \%$ ) in refluxing acetonitrile for $3 \mathrm{~h}$. Unexpectedly, 6-(2'-benzoylhydrazinyl)-1,4,5,6-tetrahydropyridazine 3aa was isolated in a $46 \%$ yield, while the anticipated 1,4-dihydropyridazine 4aa was not detected at all (Table 1, entry 1). Although the increase of the reaction time up to $5 \mathrm{~h}$ slightly improved the yield of tetrahydropyridazine 3aa (53\%, entry 2 in Table 1), more efficient appeared to be the use of a two-fold excess of benzohydrazide (2a) that provided 3aa in 93\% isolated yield after reflux for $3 \mathrm{~h}$ (Table 1, entry 4). With these optimal conditions for the synthesis of tetrahydropyridazine 3aa in hand, we next turned our attention to its transformation to 1,4-dihydropyridazine 4aa. Both the prolonged reflux for $6 \mathrm{~h}$ (Table 1, entry 5) and the addition of 100 mol $\%$ of TFA (Table 1 , entry 6 ) did not signifi- cantly promote the $\mathbf{3 a a} \rightarrow \mathbf{4 a a}$ transformation, that was apparently caused by the deactivation of the acid catalyst by ammonia, released in the preceding step (vide infra for the mechanism discussion). To prevent this process, a stepwise addition of TFA was tested (Table 1, entries 7-11). Finally, the best isolated yield of 1,4-dihydropyridazine 4aa (74\%) was achieved by a two-step, one-pot protocol, comprising the initial recyclization of hydroxypyrroline 1a with 2 equiv of benzohydrazide (2a) in refluxing acetonitrile for $3 \mathrm{~h}$ in the presence of $10 \mathrm{~mol} \%$ of TFA followed by the introduction of $140 \mathrm{~mol} \%$ of TFA and additional reflux for $3 \mathrm{~h}$ (Table 1, entry 11).

Next, the substrate scope and functional group tolerance of the protocols aimed to the chemoselective synthesis of di- and tetrahydropyridazines were investigated. Several features of the developed methods are noteworthy. It was found that all tested hydroxypyrrolines $\mathbf{1 a}-\mathbf{e}$ and hydrazides $\mathbf{2} \mathbf{a}-\mathbf{g}$ afforded the corresponding tetrahydropyridazines 3 (according to ${ }^{1} \mathrm{H}$ NMR analysis of the crude reaction mixtures). However, due to the difficulties associated with their isolation and purification only few examples of analytically pure samples were obtained in $57-93 \%$ isolated yields (Scheme 2).

When the same set of hydroxypyrrolines 1a-e and hydrazides 2a-g was subjected to the two-step, one-pot protocol, the desired 1,4-dihydropyridazines 4 were formed in $20-74 \%$ isolated yields (Scheme 3). Electron-rich hydrazides appeared to be good recyclization agents as was exemplified by the assembly of 1,4-dihydropyridazines $\mathbf{4 a b}$ and $\mathbf{4 a g}$ from 4-methylbenzohydrazide (2b) and acetohydrazide (2g) in 69\% and $54 \%$ isolated yields, respectively. In contrast, the recyclization of hydroxypyrroline 1a with electron-deficient 4-nitrobenzohydrazide (2c) proceeded somewhat less efficiently to afford the corresponding 1,4-dihydropyridazine 4ac in 44\% isolated yield. The structural fragment of the well-known antibiot- 
Table 1: A study of the model reaction between hydroxypyrroline 1a and benzohydrazide $(2 \mathrm{a})^{\mathrm{a}}$.<smiles>CC1(C)CC(O)N=C1c1ccccc1</smiles>

$1 \mathrm{a}$
TFA $(x \mathrm{~mol} \%)$ $\mathrm{MeCN}$, reflux<smiles>CC1(C)CC(NNC(=O)c2ccccc2)N(C(=O)c2ccccc2)N=C1c1ccccc1</smiles>

and/or<smiles>CC1(C)C=CN(C(=O)c2ccccc2)N=C1c1ccccc1</smiles>

3aa

4aa

\begin{tabular}{|c|c|c|c|c|}
\hline entry & TFA loading ( $x$ mol \%) & time (h) & yield of $3 \mathbf{a a}^{\mathrm{b}}$ & yield of $4 a a^{b}$ \\
\hline 1 & 10 & 3 & 46 & 0 \\
\hline 2 & 10 & 5 & 53 & 0 \\
\hline 3 & 10 & 1 & 33 & 0 \\
\hline 4 & 10 & 3 & 93 & 0 \\
\hline 5 & 10 & 6 & 92 & 0 \\
\hline 6 & 100 & 6 & \multicolumn{2}{|c|}{$3 \mathbf{a a}: 4 \mathbf{a a}=78: 22^{c}$} \\
\hline 7 & $10+40$ & $3+3$ & \multicolumn{2}{|c|}{$3 a a: 4 a a=55: 45^{c}$} \\
\hline 8 & $10+90$ & $3+3$ & \multicolumn{2}{|c|}{$3 \mathbf{a} a: 4 a a=28: 72^{c}$} \\
\hline 9 & $10+90$ & $3+4$ & \multicolumn{2}{|c|}{ 3aa:4aa = 22:78c } \\
\hline 10 & $10+90$ & $3+5$ & \multicolumn{2}{|c|}{$3 a a: 4 a a=22: 78^{c}$} \\
\hline 11 & $10+140$ & $3+3$ & \multicolumn{2}{|c|}{ 3aa:4aa $=3: 97(74 \%)^{b, c}$} \\
\hline
\end{tabular}

aReaction conditions: hydroxypyrroline $1 \mathbf{a}(95 \mathrm{mg}, 0.5 \mathrm{mmol})$, benzohydrazide (2a, $0.5 \mathrm{mmol}$ for entries 1 and 2, 1.0 mmol for entries 3-11), TFA $(x \mathrm{~mol} \%)$, acetonitrile $(3 \mathrm{~mL})$, reflux; ${ }^{b}$ if not stated otherwise, isolated yields are given; ${ }^{c}$ according to ${ }^{1} \mathrm{H}$ NMR of the crude reaction mixture.<smiles>[R]C(N)=O</smiles>

TFA (10 mol \%) $\mathrm{MeCN}$, reflux, $3 \mathrm{~h}$<smiles>[R]C(=O)NNC1CC([R])C([R])=NN1C([R])=O</smiles>

3<smiles>CC1(C)CC(NNC(=O)c2ccc([N+](=O)[O-])cc2)N(C(=O)c2ccc([N+](=O)C(C)(C)C)cc2)N=C1c1ccc([N+](=O)[O-])cc1</smiles><smiles></smiles>

3af $(60 \%)$<smiles>Cc1ccc(C2=NN(C(=O)c3ccccc3)C(NNC(=O)c3ccccc3)CC2(C)C)cc1</smiles>

3ba (58\%)<smiles>O=C(NNC1CC2(CCCCC2)C(c2ccccc2)=NN1C(=O)c1ccccc1)c1ccccc1</smiles>

3da (57\%)

Scheme 2: Synthesis of tetrahydropyridazines 3.

ic isoniazid (2f) was successfully incorporated in the tetrahydropyridazine core (the yield of 3af was $60 \%$, Scheme 2 ), but only traces of the 1,4-dihydropyridazine 4af were detected following the two-step, one-pot protocol (Scheme 3). Apparently, the basic pyridine nitrogen atoms of intermediate 3af deactivate the acid catalyst, whilst the use of 3.4 equiv of TFA causes the full protonation of the pyridine rings thus making them strongly electron-deficient substituents that finally prevent an acid-cata- 

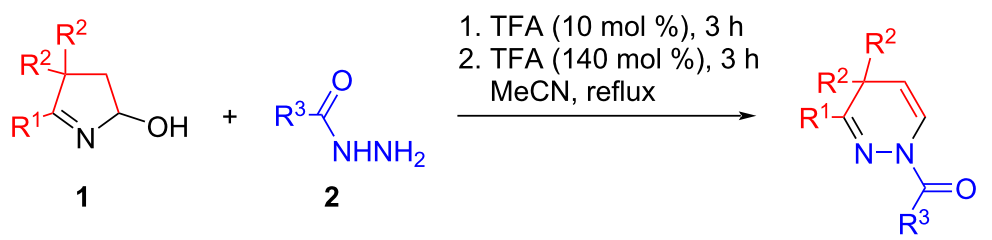

4

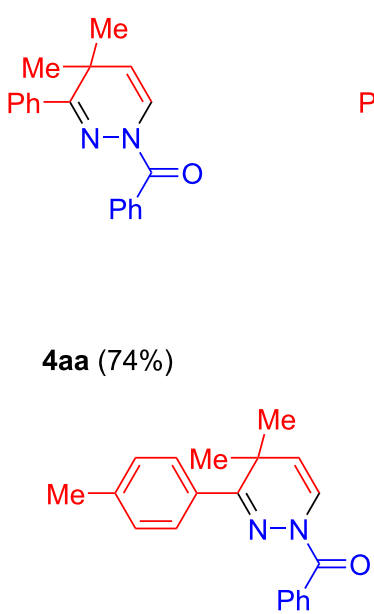

4ba (51\%)

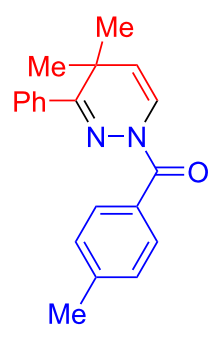

$4 a b(69 \%)$

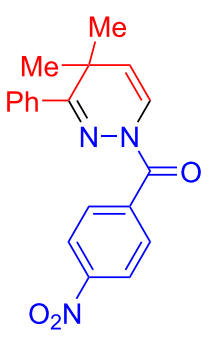

$4 \mathrm{ac}(44 \%)$

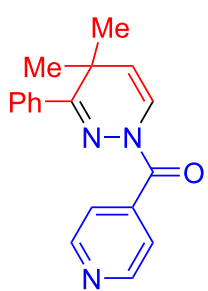

4af (traces)

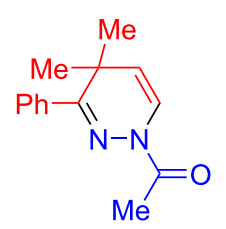

4ag (54\%)

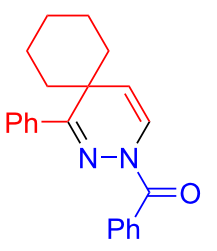

4da $(50 \%)$

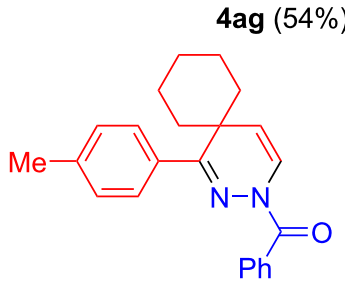

4ea $(38 \%)$

Scheme 3: Synthesis of dihydropyridazines 4 .

lyzed elimination of hydrazide $\mathbf{2 f}$ (vide infra for the mechanism discussion). Finally, the diverse hydroxypyrrolines $\mathbf{1 b}-\mathbf{e}$ were tested in the studied reaction and the corresponding 1,4-dihydropyridazines $\mathbf{4 b a}-\mathbf{e a}$ were obtained in $20-51 \%$ isolated yields.

Interestingly, when hydroxypyrroline 1a reacted under a twostep, one-pot protocol with the hydrazides of salicylic (2d) and anthranilic (2e) acids having additional nucleophilic functions, the corresponding tricycles $5 \mathbf{a d}$ and $\mathbf{5 a e}$ were formed in 53\% and $28 \%$ isolated yields, respectively (Scheme 4 ).

A proposed mechanism for the recyclization of hydroxypyrrolines 1 with hydrazides 2 is shown in Scheme 5. The proton- ation of the starting hydroxypyrroline $\mathbf{1}$ with TFA leads to the formation of cation $\mathbf{A}$, which reacts with hydrazide $\mathbf{2}$ to give the pyrrolidine derivative $\mathbf{B}$. The latter undergoes a ring opening with formation of the linear intermediate $\mathbf{C}$. In comparison with alkyl-, aryl-, and hetarylhydrazines [11] as well as semicarbazide and its derivatives [12], the nucleophilicity of the internal nitrogen atom of hydrazide $\mathbf{2}$ is significantly reduced. As a result, the interception of the intermediate $\mathbf{C}$ by the second molecule of hydrazide $\mathbf{2}$ affords dihydrazone $\mathbf{D}$ (similar to previously observed in the recyclization with 2,4-dinitrophenylhydrazine [11]), which further cyclizes to tetrahydropyridazine 3 . An acid-catalyzed elimination of hydrazide $\mathbf{2}$ from tetrahydropyridazine $\mathbf{3}$ completes the formation of 1,4-dihydropyridazine 4.

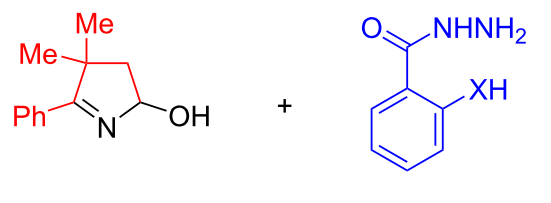

1a
1. TFA $(10 \mathrm{~mol} \%), 3 \mathrm{~h}$

2. TFA $(140 \mathrm{~mol} \%), 3 \mathrm{~h}$ $\mathrm{MeCN}$, reflux

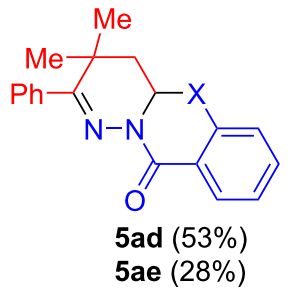




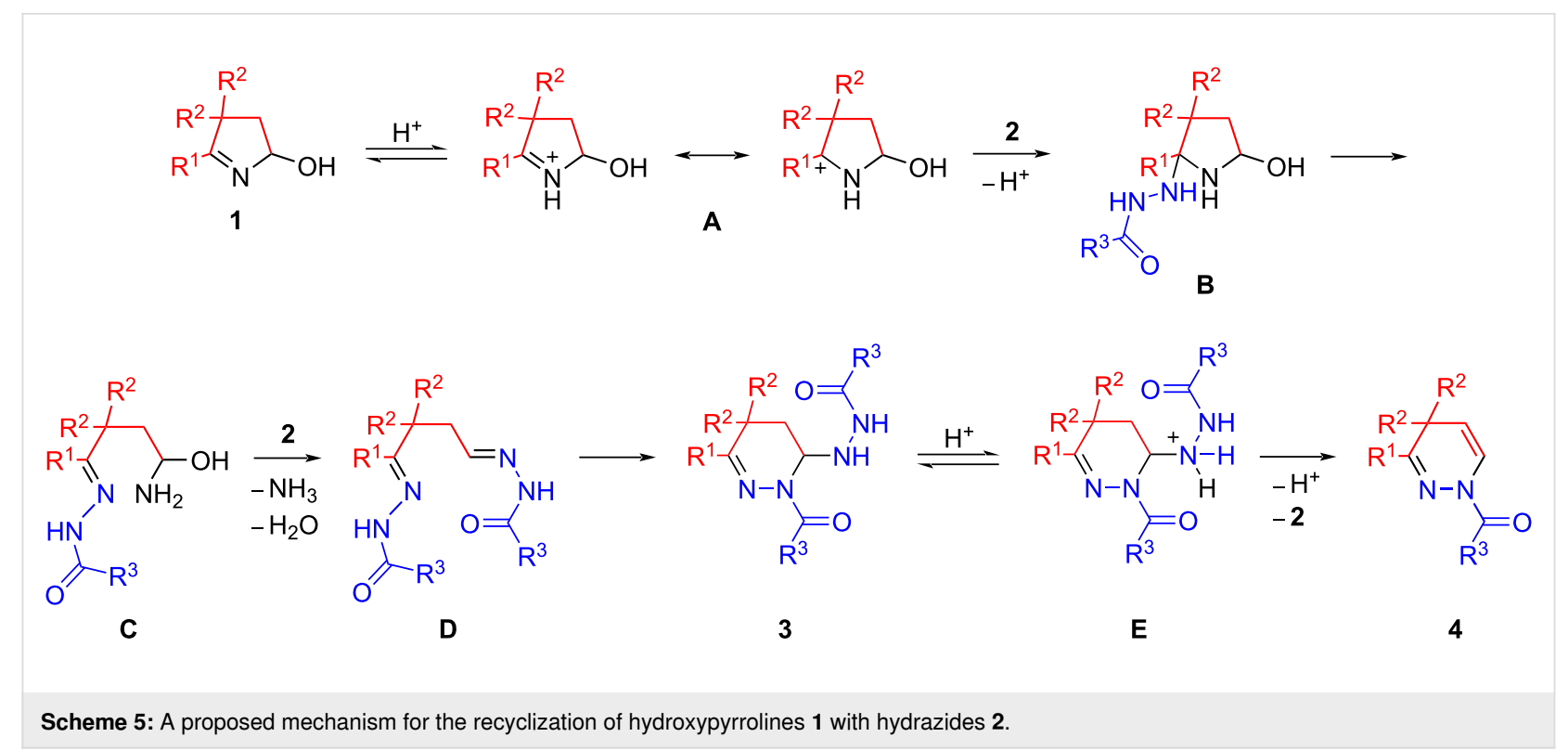

\section{Conclusion}

In summary, an acid-catalyzed recyclization of hydroxypyrrolines (easily synthesized from ketoximes and acetylene) with hydrazides was studied. The reduced nucleophilicity of the hydrazides in comparison with other hydrazine derivatives constitutes the basis for the convenient chemoselective syntheses of highly functionalized azaheterocyclic scaffolds (di- and tetrahydropyridazines) with an acyl function at the nitrogen atom, thus having a substituent pattern similar to that of the known biologically active compounds of the pyridazine family. Moreover, the presence of other nucleophilic functions in the hydrazide component creates diversification points and enables more complex molecular architectures to be assembled that was demonstrated by the synthesis of partially saturated azatricyclic systems.

\section{Supporting Information}

\section{Supporting Information File 1}

Experimental methods, compound characterization data, and copies of ${ }^{1} \mathrm{H}$ and ${ }^{13} \mathrm{C}$ NMR spectra.

[https://www.beilstein-journals.org/bjoc/content/ supplementary/1860-5397-17-29-S1.pdf]

\section{Acknowledgements}

The spectral data were obtained with the equipment of the Baikal Analytical Center for collective use SB RAS. ESIHRMS-TOF spectra were recorded at Shared Research Facilities for Physical and Chemical Ultramicroanalysis, Limnological Institute, SB RAS.

\section{Funding}

The reported study was funded by RFBR according to the research project No. 18-33-00089.

\section{ORCID ${ }^{\circledR}$ iDs}

Dmitrii A. Shabalin - https://orcid.org/0000-0002-0685-9508

\section{References}

1. Zhang, L.; Williams, M. A.; Mendel, D. B.; Escarpe, P. A.; Chen, X.; Wang, K.-Y.; Graves, B. J.; Lawton, G.; Kim, C. U.

Bioorg. Med. Chem. Lett. 1999, 9, 1751. doi:10.1016/s0960-894x(99)00280-2

2. Combs, D. W.; Reese, K.; Phillips, A. J. Med. Chem. 1995, 38, 4878-4879. doi:10.1021/jm00025a003

3. Combs, D. W.; Reese, K.; Cornelius, L. A. M.; Gunnet, J. W.; Cryan, E. V.; Granger, K. S.; Jordan, J. J.; Demarest, K. T. J. Med. Chem. 1995, 38, 4880-4884. doi:10.1021/jm00025a004

4. Chiou, G. C. Y.; Yao, Q. S.; Okawara, T. J. Ocul. Pharmacol. Ther. 1994, 10, 577-586. doi:10.1089/jop.1994.10.577

5. Frankowiak, G.; Meyer, H.; Bossert, F.; Heise, A.; Kazda, S.; Stoepel, K.; Towart, R.; Wehinger, E. 1,4-Dihydropyridazine compounds. U.S. Patent 4,348,395, Sept 7, 1982.

6. Loev, B.; Jones, H.; Shroff, J. R. N-Substituted 1,4-dihydropyridazines and pharmaceutical compositions. U.S. Patent 4,435,395, March 6, 1984.

7. Vogel, A. 4-(2,1,3-Benzoxadiazol-4-yl)-1,4-dihydropyridazine derivatives, their production and pharmaceutical compositions. U.S. Patent 4,491,581, Jan 1, 1985.

8. Shabalin, D. A.; Dvorko, M. Y.; Schmidt, E. Y.; Ushakov, I. A.; Trofimov, B. A. Tetrahedron 2016, 72, 6661-6667. doi:10.1016/j.tet.2016.08.088

9. Shabalin, D. A.; Dvorko, M. Y.; Schmidt, E. Y.; Protsuk, N. I.; Trofimov, B. A. Tetrahedron Lett. 2016, 57, 3156-3159. doi:10.1016/j.tetlet.2016.06.025

10. Shabalin, D. A.; Dubovtsev, A. Y.; Schmidt, E. Y.; Trofimov, B. A. ChemistrySelect 2020, 5, 3434-3437. doi:10.1002/slct.202000392 
11. Shabalin, D. A.; Dvorko, M. Y.; Zolotareva, E. E.; Ushakov, I. A.; Vashchenko, A. V.; Schmidt, E. Y.; Trofimov, B. A. Eur. J. Org. Chem. 2017, 4004-4010. doi:10.1002/ejoc.201700589

12. Shabalin, D. A.; Ivanova, E. E.; Kuzmin, A. V.; Dvorko, M. Yu.; Schmidt, E. Yu.; Trofimov, B. A. Synthesis 2018, 50, 4982-4988. doi:10.1055/s-0037-1610239

13. Narang, R.; Narasimhan, B.; Sharma, S. Curr. Med. Chem. 2012, 19, 569-612. doi:10.2174/092986712798918789

14. Verma, G.; Marella, A.; Shaquiquzzaman, M.; Akhtar, M.; Ali, M. R.; Alam, M. M. J. Pharm. BioAllied Sci. 2014, 6, 69-80. doi:10.4103/0975-7406.129170

15. Popiołek, Ł. Med. Chem. Res. 2017, 26, 287-301. doi:10.1007/s00044-016-1756-y

16. Wahbeh, J.; Milkowski, S. SLAS Technol. 2019, 24, 161-168. doi:10.1177/2472630318822713

17. Lovering, F.; Bikker, J.; Humblet, C. J. Med. Chem. 2009, 52 , 6752-6756. doi:10.1021/jm901241e

\section{License and Terms}

This is an Open Access article under the terms of the Creative Commons Attribution License

(https://creativecommons.org/licenses/by/4.0). Please note that the reuse, redistribution and reproduction in particular requires that the author(s) and source are credited and that individual graphics may be subject to special legal provisions.

The license is subject to the Beilstein Journal of Organic Chemistry terms and conditions:

(https://www.beilstein-journals.org/bjoc/terms)

The definitive version of this article is the electronic one which can be found at: https://doi.org/10.3762/bjoc.17.29 